\title{
MDCT and Ultrasound Evaluation of Primary Masses of Neck with Pathological Correlation
}

\author{
Dr. Sujata Patnaik ${ }^{1}$, Ramesh Allada ${ }^{2}$, Dr. Y Jyostna ${ }^{3}$, Dr. Phani Chakravarthy ${ }^{4}$, \\ Dr. Shantiveer $\mathrm{U}^{5}$, Dr. S Ramamurti ${ }^{6}$ \\ ${ }^{1,2,3,4,6}$ Department Of Radiology \& Imageology, Nizam's Institute Of Medical Sciences, Hyderabad, India \\ ${ }^{5}$ Department of Pathology, Nizam's Institute of Medical Sciences, Hyderabad, India
}

\begin{abstract}
Neck masses are often encountered in clinical practice. Imaging plays a great role in diagnosing it depending on age of presentation, site, imaging morphology in various modalities especially ultrasonography(USG) and CT. The extent, nature of lesion whether benign or malignant are better depicted on CT scan. Sometimes biopsy/FNAC is needed for final diagnosis. We evaluated 70 consecutive patients of neck masses presenting to our department. All patients had undergone USG followed by MDCT Scan. All were proven histopathologically and were correlated. Demographic profile, type of various pathology and their characteristic imaging findings were analysed. Majority were in age group 41-60 years and female predominated over male. Thyroid lesions constituted $60 \%$ followed by neurogenic (12.8\%), paragangliomas (8.6\%), congenital lesions (branchial cleft cyst, Thyroglossal cyst, Ectopic thyroid) in 8.6\%. Other lesions were salivary gland neoplasms and hemangiopericytoma. Among the thyroid masses benign lesions constituted the majority. Characteristic site, shape and imaging morphology clinch the diagnosis in most of the cases.
\end{abstract}

Keywords: Neck masses, benign/malignant lesions, FNAC/biopsy, Thyroid mass, USG, MDCT

\section{Introduction}

Mass in neck is a common clinical problem and its diagnosis based on imaging techniques is often undertaken prior to FNAC or biopsy. A radiological study of the spectrum of possible pathologies can largely help the clinicians to diagnose and prognosticate when a patient present with a mass in neck. We had undertaken this study with an aim to establish the demographic profile of the neck masses (incidence, age and sex distribution) and to study the Ultrasound and MDCT features of different primary neck masses with pathological correlation.

\section{Materials and methods}

The study was carried out in the Department of Radiology and Imageology, Nizam's Institute of Medical Sciences, Hyderabad. Total period of study was 1.5 years (from March 2013 to August 2014). The study included 70 patients, which were referred for CT with clinical history/USG findings of neck mass/swelling. CT was done for the patients in NCCT and CECT phases. Patient demographic data, clinical symptoms, USG, CT characteristics were recorded, and compared with pathological findings. Patients were evaluated with MDCT (PHILIP'S BRILIANCE 16) (Both plain and contrast scans of neck) and Ultrasonography (E-Saote).

\section{Results}

The study group consisted of 70 patients which included 45 females; the maximum was in the age group of 41 to 60 years. Thyroid lesions constituted the majority of neck masses $(60 \%)$ followed by neurogenic tumours, paragangliomas, congenital and salivary gland masses (Table-1).

Table -1: Types of neck masses [Benign -34; malignant -8)

\begin{tabular}{|l|l|l|l|l|l|l|}
\hline Age & $0-20$ & $21-40$ & $41-60$ & $61-80$ & Above 80 & No.Of Ases $(\%)$ \\
\hline Thyroid & 0 & 9 & 18 & 14 & 1 & $42(60 \%)$ \\
\hline Neurogenic & 2 & 4 & 3 & 0 & 0 & $09(12.8 \%)$ \\
\hline Paraganglioma & 0 & 2 & 3 & 1 & 0 & $06(8.5 \%)$ \\
\hline Branchial Cleft Cyst & 0 & 3 & 0 & 0 & 0 & $03(4.2 \%)$ \\
\hline Ectopic Thyroid & 1 & 0 & 0 & 0 & 0 & $01(1.4 \%)$ \\
\hline Thyroglossal Cyst & 1 & 0 & 0 & 1 & 0 & $02(2.8 \%)$ \\
\hline Salivary Gland & 1 & 2 & 0 & 0 & 1 & $04(5.7 \%)$ \\
\hline Lymphangioma & 1 & 1 & 0 & 0 & 0 & $02(2.8 \%)$ \\
\hline Hemangiopericytoma & 0 & 0 & 0 & 1 & 0 & $01(1.4 \%)$ \\
\hline
\end{tabular}


3.1. Thyroid masses

Thyroid mass constitutes majority of neck masses. Maximum are in age group of 41 to 60 followed by 21 to 40 years. Females predominated over males. Benign thyroid nodules constituted $80 \%$ and rest are malignant lesions. The CT and US features of the malignant thyroid masses are detailed in Table- 2 .

Table-2: CT/US morphology of malignant thyroid masses

\begin{tabular}{|c|c|c|c|}
\hline Feature & $\begin{array}{l}\text { Papillary } \\
\text { Carcinoma } \\
(\mathrm{N}=5)\end{array}$ & $\begin{array}{l}\text { Follicular } \\
\text { Carcinoma } \\
(\mathrm{N}=3)\end{array}$ & Remarks \\
\hline $\begin{array}{l}\text { Echo Texture- Iso } \\
\text { Hypo }\end{array}$ & $\begin{array}{l}2 \\
3 \\
\end{array}$ & $\begin{array}{l}2 \\
1 \\
\end{array}$ & $\begin{array}{l}\text { Most Of Papillary Ca Are } \\
\text { Hypoechoic }\end{array}$ \\
\hline $\begin{array}{l}\text { Consistency Solid } \\
\text { Cystic }\end{array}$ & $\begin{array}{l}4 \\
1\end{array}$ & $\begin{array}{l}3 \\
0\end{array}$ & \\
\hline Lymph Nodes & 3 & 1 & \\
\hline Vascularity Increase & 4 & 3 & \\
\hline Halo Sign & 0 & 1 & \\
\hline Calcification & 1 & 0 & \\
\hline Invasion To Adj & 0 & 1 & \\
\hline Metastasis & 0 & 3 & $\begin{array}{l}\text { Follicular Ca Present With } \\
\text { Metastasis }\end{array}$ \\
\hline
\end{tabular}

Papillary carcinoma was more common appearing predominantly hypoechoic, increased vascularity and no invasion to adjacent structure as compared to follicular carcinoma appearing isoechoic, solid with increased vascularity and metastases. Only 1 case of papillary carcinoma showed calcification. The malignant nature was diagnosed on radiological presentation and confirmed histopathologically in all cases. CT depicted the invasive nature and metastasis. Rest of the features are common in both CT and Ultrasound.

\subsection{Neurogenic tumours (Table-3)}

The imaging features of our neurogenic masses are depicted in table-3. All neurofibromas were infrahyoid and majority of schwannoma were infrahyoid in location; Majority showed variable heterogeneous enhancement. None had any calcification. All are having characteristic shape.

Table-3: Ct/Us Features Of Neurogenic Tumours

\begin{tabular}{|l|l|l|ll|}
\hline Feature & $\begin{array}{l}\text { Schwannoma } \\
(\mathrm{N}=3)\end{array}$ & $\begin{array}{l}\text { Neurofibroma } \\
(\mathrm{N}=6)\end{array}$ & Remarks \\
\hline Shape-Fusiform & 3 & 6 & All Are Fusiform & \\
\hline Site- & & 0 & & \\
Suprahyoid & 1 & 6 & Most Of Cases \\
Infrahyoid & 2 & & Heterogenous & \\
\hline & & 3 & & \\
Hypodense & 1 & 6 & & \\
Heterogenous & 2 & 6 & & \\
\hline Enhancement & 3 & 0 & & \\
\hline Calcification & 0 & 3 & & \\
\hline Mass Effect & 1 & & & \\
\hline
\end{tabular}

\subsection{Imaging findings in paragangliomas (CT/MRI)}

The paragangliomas $(\mathrm{n}=6)$ were confined to suprahyoid location in 3 and were extending throughout in the rest. Mass effect with characteristic splaying of ICA and ECA was seen in 5/6 cases. But for one all showed intense homogenous enhancement. Heterogeneous enhancement was noted in 1.

\subsection{Congenital /developmental masses- imaging}

Out of 3 branchial cleft cysts 2 were supra hyoid and 1 infrahyoid, 2 cases of thyroglossal cysts were at hyoid level and at midline/paramedian location. Branchial cleft cysts were hypodense with minimal enhancement whereas the thyroglossal cysts were minimally enhancing hypodense mass. Ectopic thyroid was noted in 1 case at midline appearing hyperechoic on USG and hyperdense on CT.

\subsection{Salivary gland masses}

Two were pleomorphic adenomas in parotid appearing heterogeneous enhancing mass and 1 was submandibular carcinoma having infiltrating border, mixed echoic/ dense enhancing SOL. There was a case of sialolithiasis with inflammatory changes in surrounding tissue. 


\subsection{Other masses}

There were 2 cases of lymphangioma in infrahyoid compartment appearing cystic, septated and minimal enhancement on contrast enhanced CT. A case of hemangiopericytoma was observed. The SOL was infrahyoid in posterior triangle. Lesion was cystic with septation, no vascularity on Doppler USG. CT showed hypodense peripherally enhancing lesion.

\section{Discussion}

Ezzat et al have studied the prevalence of thyroid masses in 100 patients and found that thyroid abnormalities presented most often as incidental abnormalities as our series (fig 1). $80 \%$ of thyroid masses were benign nodule [1]. According to Jindal et al in their 350 cases of head and neck swellings in rural Indian population, that underwent FNAC, lymph node enlargements $(50.85 \%)$ and thyroid lesions $(22.85 \%)$ are the most common [2]. Reede in a study of 44 cases found nodal masses and thyroid masses as the most common followed by neurogenic and connective tissue related masses [3].

Papillary carcinoma is the most common malignant lesion (70\%) among the malignant thyroid lesions, followed by follicular carcinoma (10-20\%). Papillary carcinomas are more common in women as seen in our study ( Fig2). Papillary Carcinoma usually presents as a solitary mass with irregular outline, increase vascularity and small punctuate calcifications [4,5]. Follicular Carcinoma appears isoechoic in 55\% and hypoechoic in $45 \%$ cases (Fig 3,4) [6]. Invasion to surrounding structures and characteristic vascular pattern in intra-nodular and peri-nodular vessels (on Doppler) can differentiate benign from malignant lesion. CT demonstrates the infiltration to adjacent structures and metastases. Our series also demonstrates similar findings - most of the papillary carcinomas are hypoechoic and follicular carcinomas are isoechoic with increased vascularity both at the centre and the periphery. All the 3 follicular ca had metastasis at presentation (Fig 4).
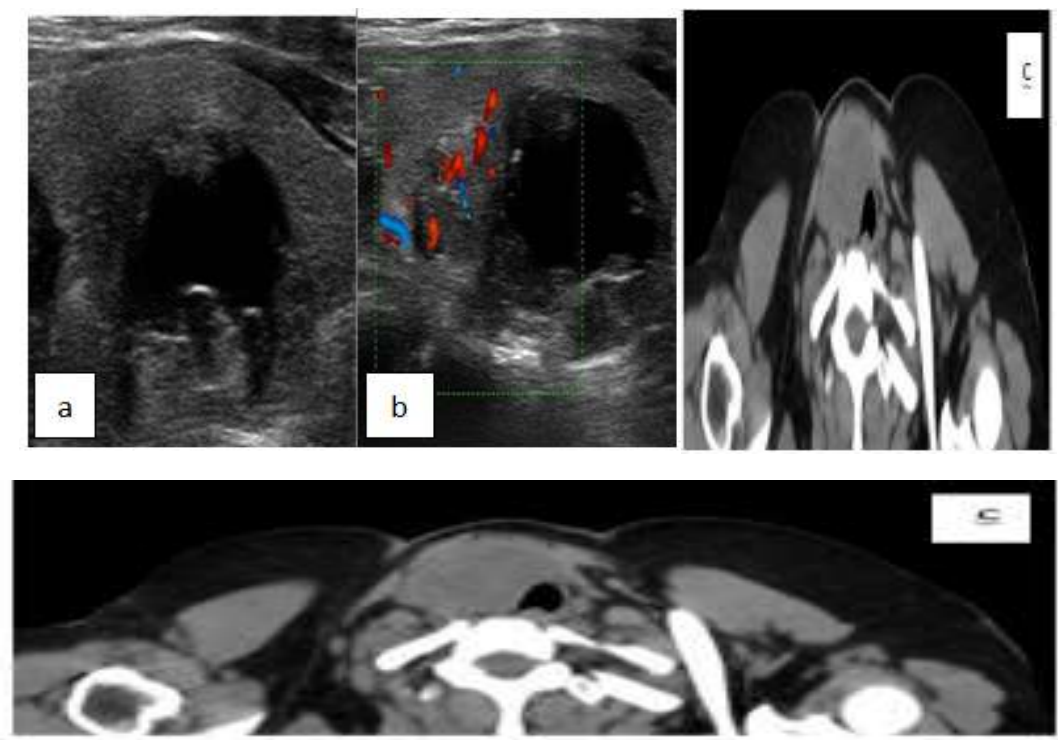

Fig 1: a and b- Ultrasound and Doppler images of benign thyroid nodule appearing cystic with peripheral vascularity. c,d - CT Scan of same patient showing well defined hypodense minimally peripherally enhancing lesion.
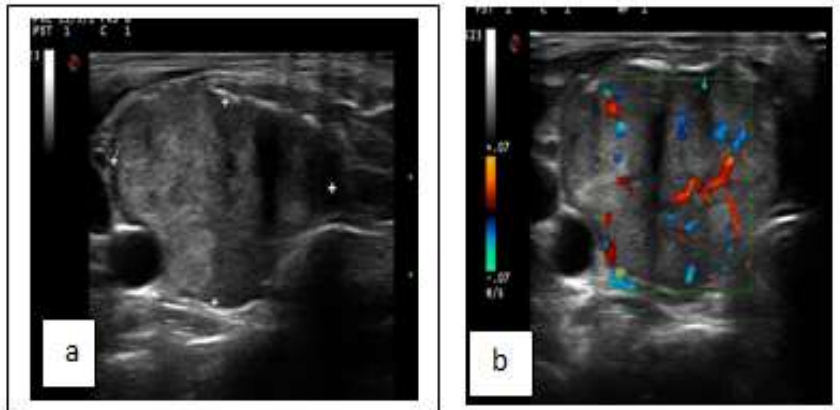

Fig 2: 78-year female ultrasound demonstrates large mixed echoic SOL with extensive intrinsicvascularity suggestive of malignant lesion. 

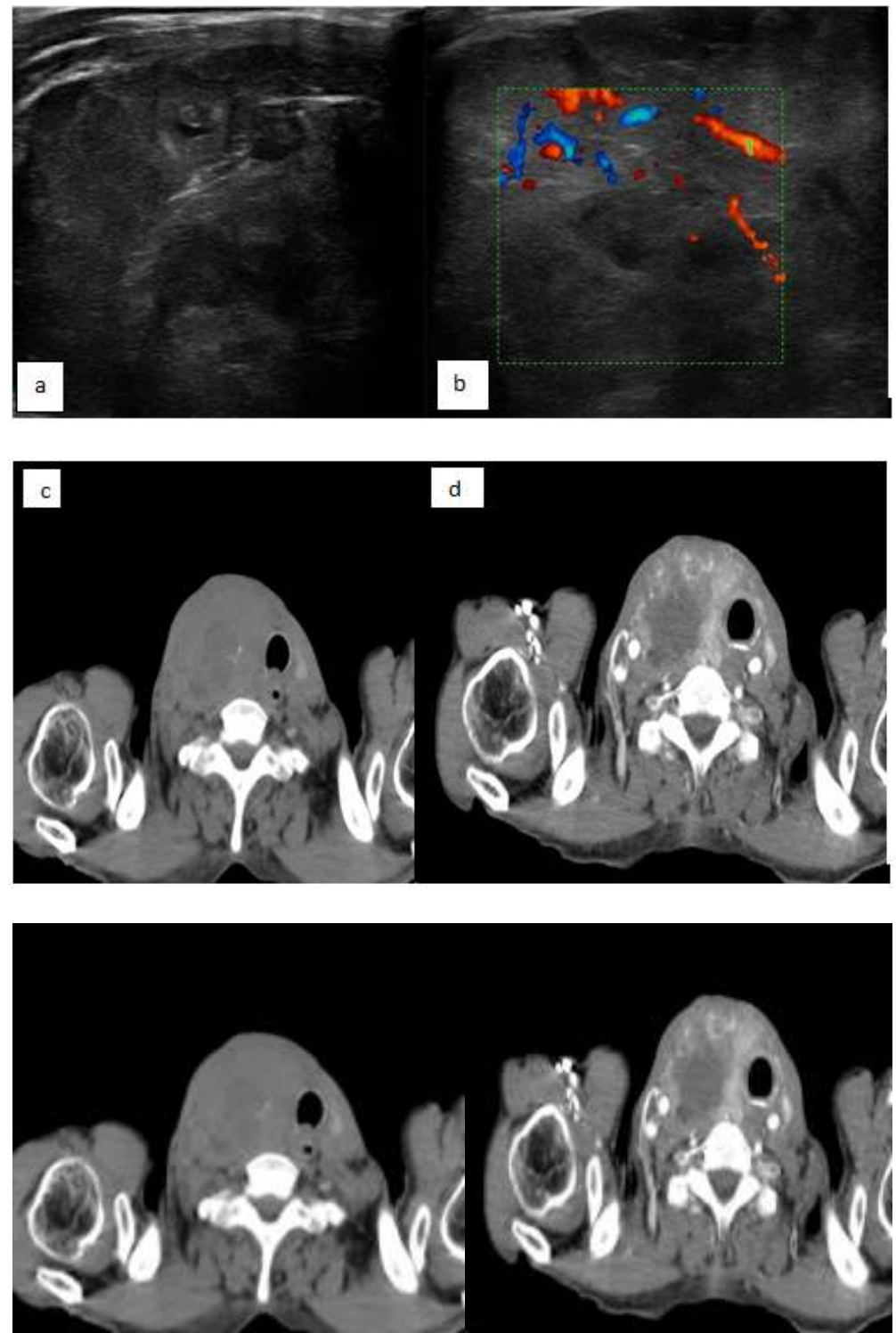

Fig 3: $a$ and b- 62 years male presenting with neck mass. HPE proven Follicular carcinoma. USG typically reveals large ill-defined predominantly hypoechoic sol having marked intrinsic vascularity suggestive malignant lesion; $\mathrm{c}$ and $\mathrm{d}$ are CT Scan of same depicting the marked peripheral enhancement with capsular invasion.

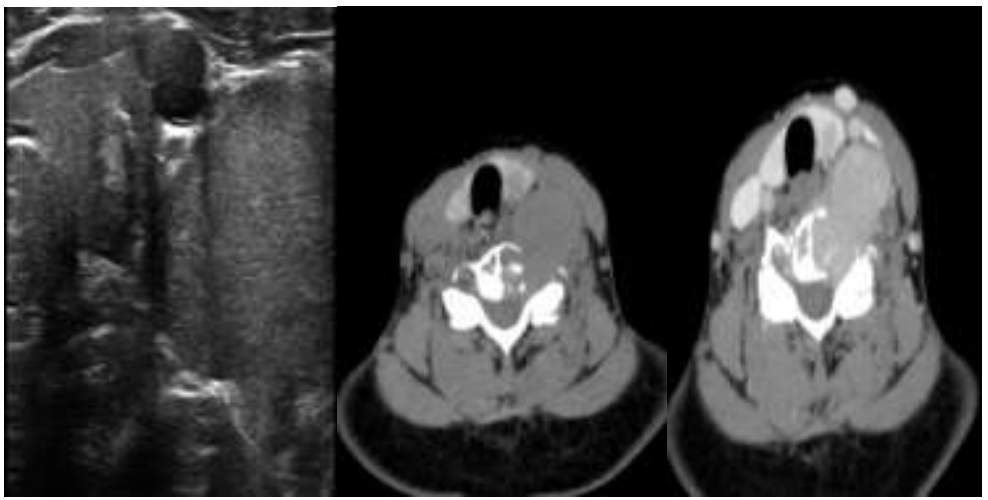

Fig 4: $\mathrm{a}$ and $\mathrm{b}$ - are CT scan images of 35 years old male diagnosed as follicular carcinoma and presented with osseous metastasis. Fig- a, b are CT Scan showing small thyroid nodule in left lobe and lytic lesion with large enhancing soft tissue component. on USG primary mass appearing hyperechoic and soft tissue component of spinal metastasis appearing as lase isoechoic lesion. 
Extra cranial Schwannomas are common in neck with the most of them being in the midline. On CT they appear isodense to muscle with variable enhancement in majority of the cases. But some of them may be cystic with fluid-fluid level in some of the cases [7]. Three of our series are infrahyoid with tissue characteristic similar to the above study (Fig 5).
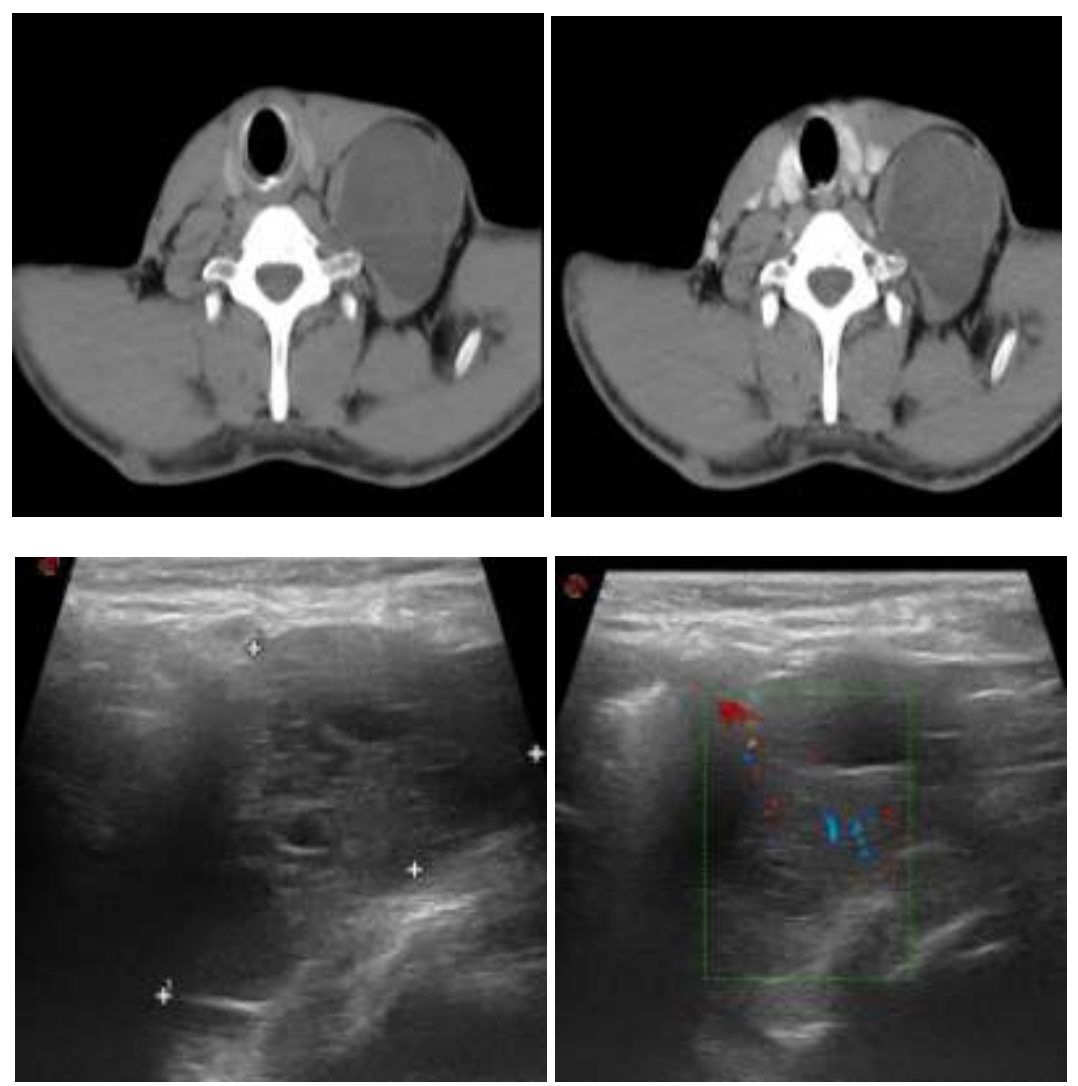

Fig 5: a, b, c, d.-36-year male diagnosed to have neurofibroma in left lower neck. The lesion on CT Scan appear well defined hypodense minimally enhancing lesion and on USG (c,d ) depicts the cystic anechoic and solid isoechoic component. Doppler also reveals minimal vascularity.

Imaging features of the Neurofibroma reflects the underlying histology attributed to collagen with elongated spindle cells. On CT the hypo attenuation areas appearing cystic due to lipid rich Schwann cells. All our cases showed heterogeneous attenuation and enhancement on CT and USG (Fig 5,6). Due to vertically oblong shape and enhancement pattern they are differentiated from paragangiomas. These findings are similar to the observations by Gopinathan et al [8]. Paragangiomas are slow growing vascular tumours, seen along the carotid space and are also known as Carotid body tumour, Glomus Vagale, Glomus jugular tumours [9]. According to the site of origin, typical internal enhancement i.e. Salt and pepper appearance due to multiple vascular channels are characteristic. All the cases in our series are classical in location, mass effect and enhancement pattern (Fig 7).
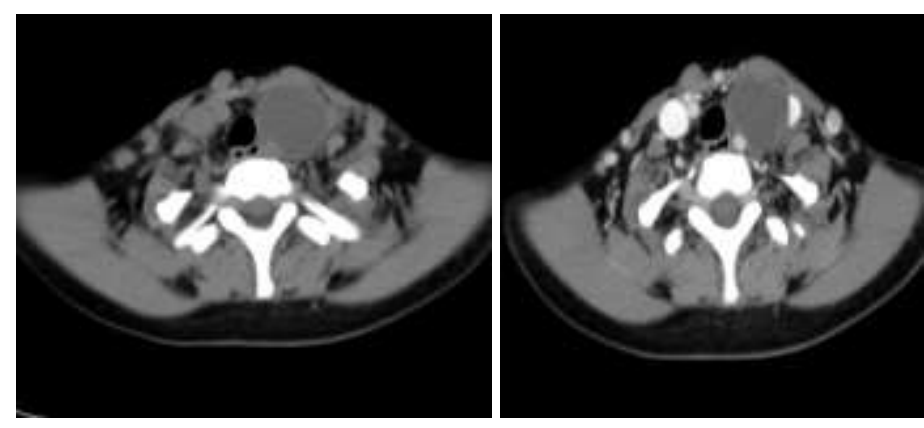

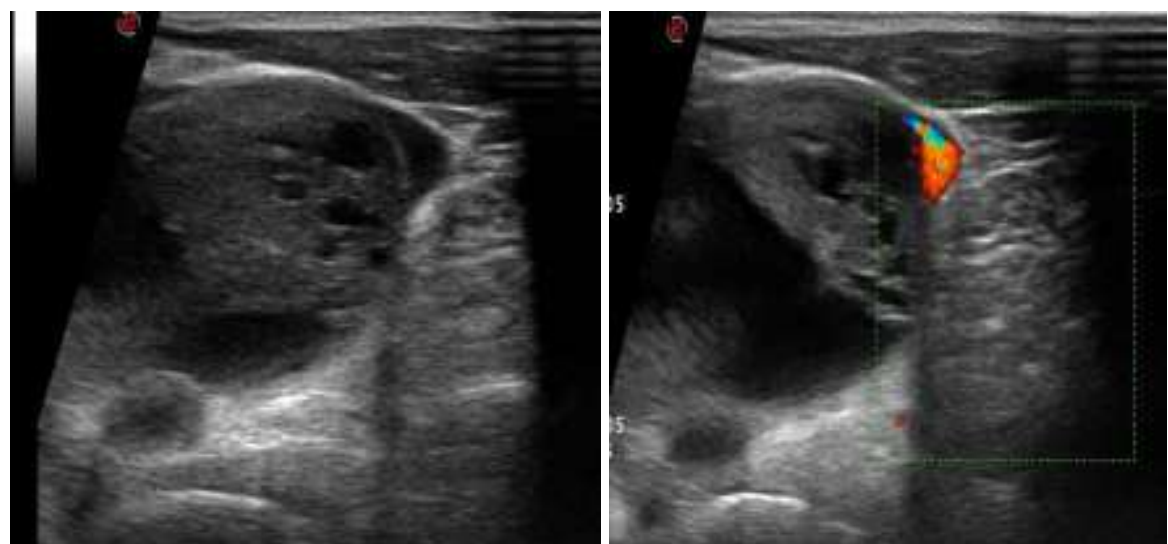

Fig 6: a b- $33 \mathrm{~F}$ a case of Schwannoma. CT Scan, lesion is well circumscribed hypodense with minimal enhancement and on USG (c,d ) it appear to be characteristically cystic solid with peripheral vascularity.
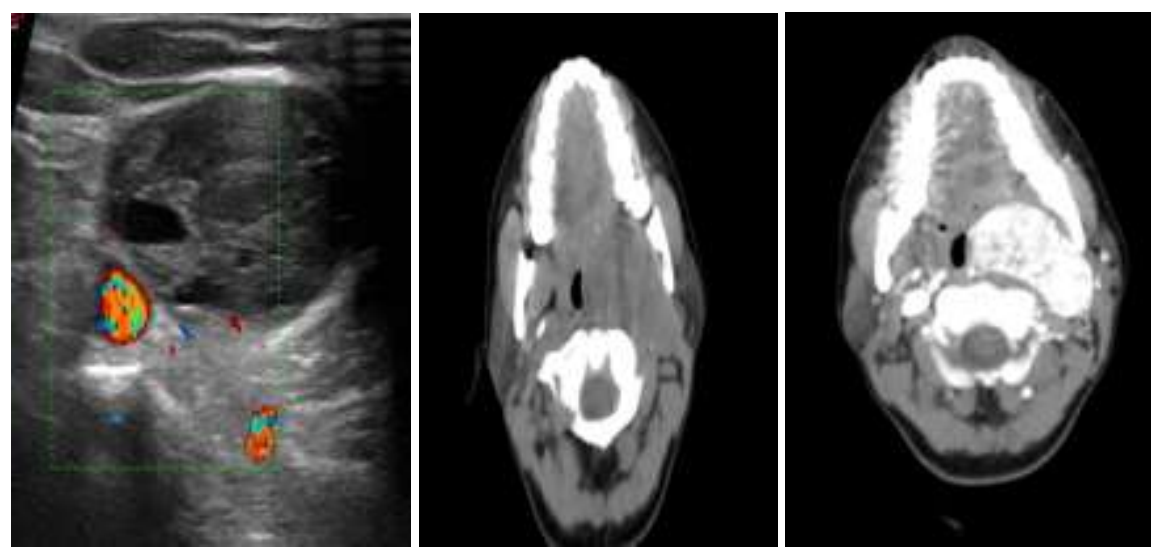

Fig 7: a case of paragangliomas in 62-year M. USG demonstrates medial displacement of CCA and lateral displacement of IJV by well circumscribed hypoechoic SOL. On CT Scan the lesion is characteristically brilliantly enhancing.

The brachial cleft cysts are due to incomplete obliteration of a part of the brachial apparatus. The first brachial cleft cysts arise from residual embryonic tract which extend from external auditory canal to the parotid gland to submandibular region. Type I is usually peri-auricular in location and type-II is peri-parotid external to and from the external auditory canal to the angle of mandible. Most common is inferior to the angle of mandible displacing sternocleidomastoid, carotid artery, Jugular Vein medially and sub-mandibular gland anteriorly. The second brachial anomalies are the most common and can cause fistulae, sinuses and cysts. They occur anywhere between tonsillar fossa to supraclavicular region. Third and fourth brachial cysts are rare [10]. Our observation also was similar to the above findings. Our cases were type 2 and periparotid in location (Fig 8).
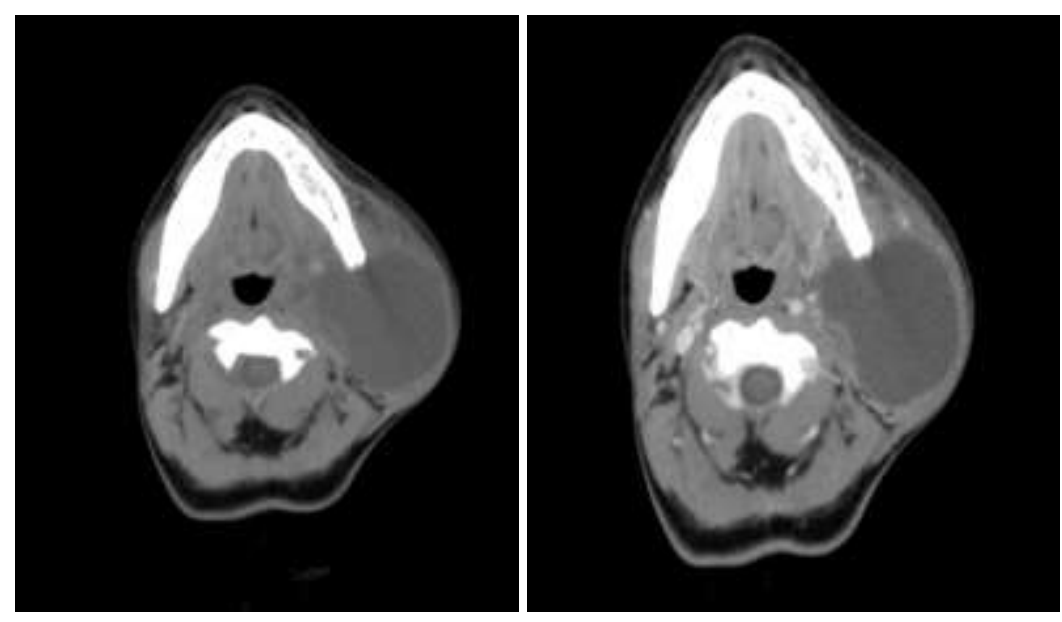


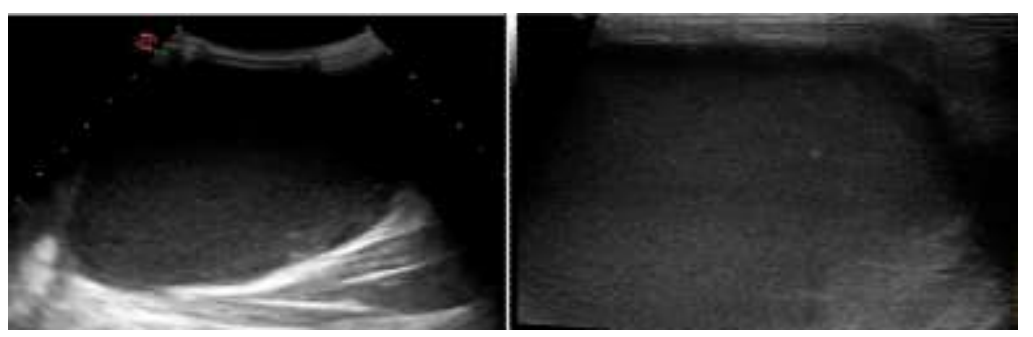

Fig 8: 35 years old female present with soft neck swelling and proven to be Branchial cleft cyst. CT Scan reveals well defined non-enhancing SOL of fluid density close to submandibular gland. On USG the lesion is having echogenic debris and no vascularity.

The thyroglossal cysts are the most common congenital lesions in neck [11]. It is the remnant of thyroglossal duct it can lie anywhere from foramen caecum of tongue to thyroid bed in midline/ paramedian location, closely related to hyoid bone (can be infrahyoid or suprahyoid). Smooth thin walled and well defined cystic lesion is the characteristic feature. Occasionally septated with rim enhancement. If it is infected it may be seen as heterogeneous lesion. 2 cases of thyroglossal cyst, we observed are at midline/just paramedian and are at thyroid cartilage level(Fig9). Ectopic thyroid was noted in 1 case at midline appearing hyperechoic on USG, hyperdense on CT close to hyoid (Fig 10). According to literature, thyroid ectopia is categorised into one of 4 typical locations with respect to embryologic course a. base of tongue, b. adjacent to hyoid bone, c. midline infrahyoid location, d. rarely lateral aspect of neck.

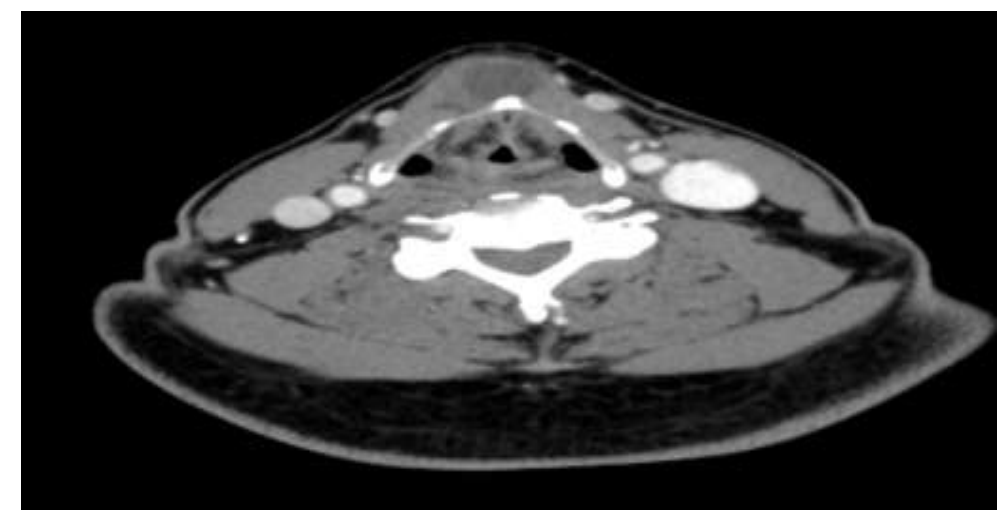

Fig 9: 10 years old male child presenting as well defined hypodense minimally enhancing sol of fluid density at midline in ventral aspect of thyroid cartilage surgically proven to be Thyroglossal cyst.
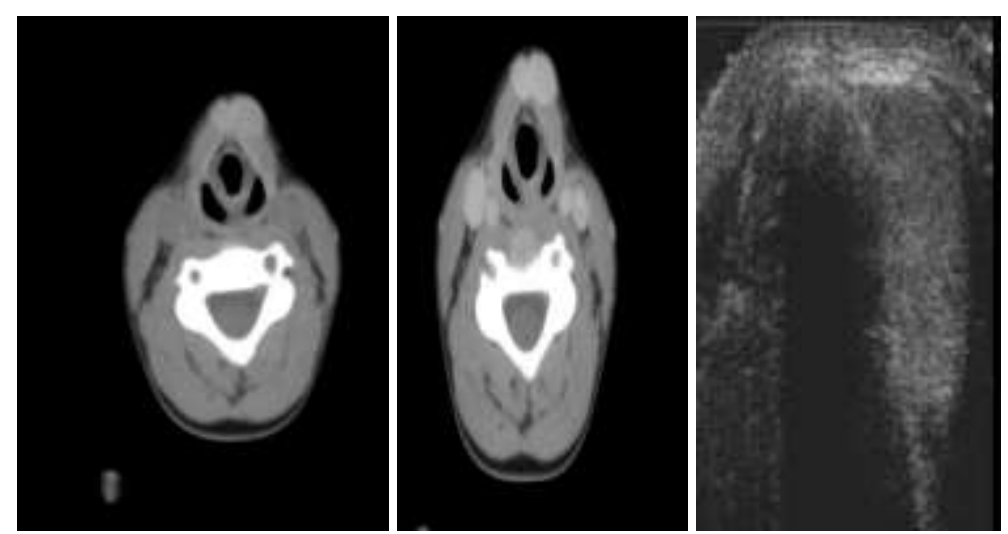

Fig 10: a, b- represent non-enhanced and contrast enhanced CT Scan of neck in 9 years old child. Bilobed hyperdense enhancing thyroid in ectopic location at mid line. Same lesion appears hyperechoic on USG.

Pleomorphic adenomas appear later in childhood or adolescence as hard mobile and painless masses. Hypoechoic or relatively isoechoic may contain calcification. On CT/MRI the lesion is well encapsulated, rounded homogenous soft tissue with mild hyperintensity on T2 weighted images. We also had similar experience.

Carcinomas of the salivary gland present as lobulated mass of mixed signal with cysts, necrosis, infiltrating margins. In $90 \%$ cases sialolithiasis occurs in submandibular gland. It is most common cause of 
inflammatory mass in sub-mandibular gland due to its upwards secretion. These findings were similar to our series (Fig 11). Most of the lymphangioma are cystic hygroma and $75 \%$ of them occur in neck, centred in posterior triangle or submandibular space. These lesions show infiltrative borders, do not respect fascial planes and are cystic in nature. Sometimes they demonstrate fluid-fluid level [12]. Two of our cases showed typical features and had not shown fluid-fluid levels (Fig 12).

Hemangiopericytoma known as solitary fibrous tumour is a rare neoplasm of mesenchymal origin. The majority are benign $(80 \%)$. CT reveals well circumscribed smooth, lobulated soft tissue mass that may contain calcium. Smaller lesions enhance homogeneously whereas larger ones may have central low attenuation, cystic or necrotic areas as seen in our case (Fig13) [13].
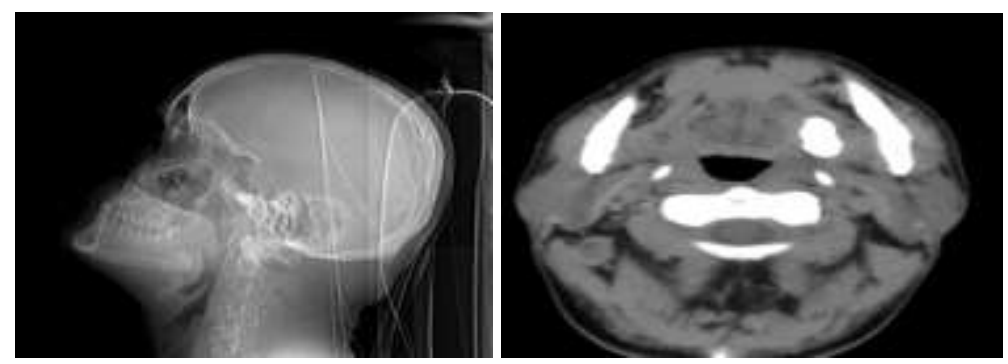

Fig 11: a, b- 38 years old male had swelling in submandibular region. Topogram and axial CT section reveal a large submandibular calculus

Fig 11-c is USG image clearly shows the calculus and adjacent inflammatory mass.
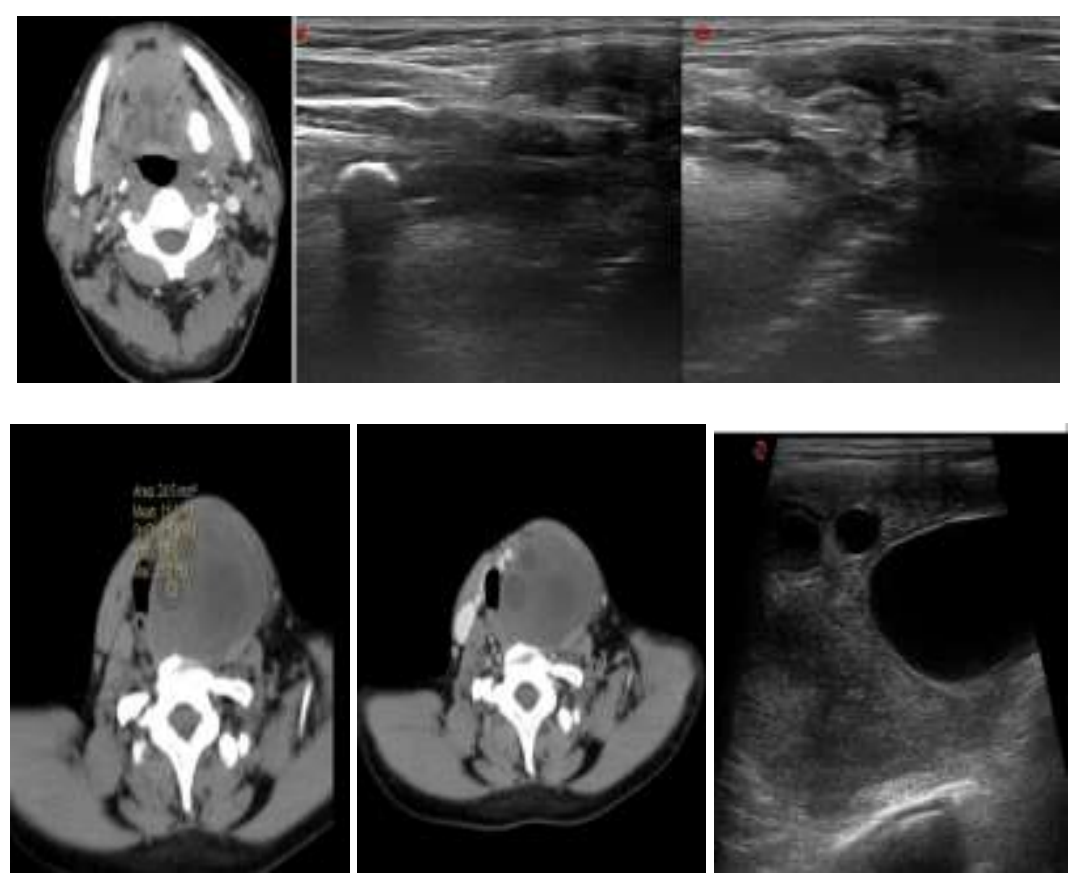

Fig 12 Case of lymphatic malformation in 36 year /F. CT Scan (a, b) typically depicting hypodense SOL of fluid attenuation, multiple septatation and no appreciable enhancement on contrast administration. USG (c, d) showing multiple cystic lesion with intervening solid isoechoic component and no vascularity.
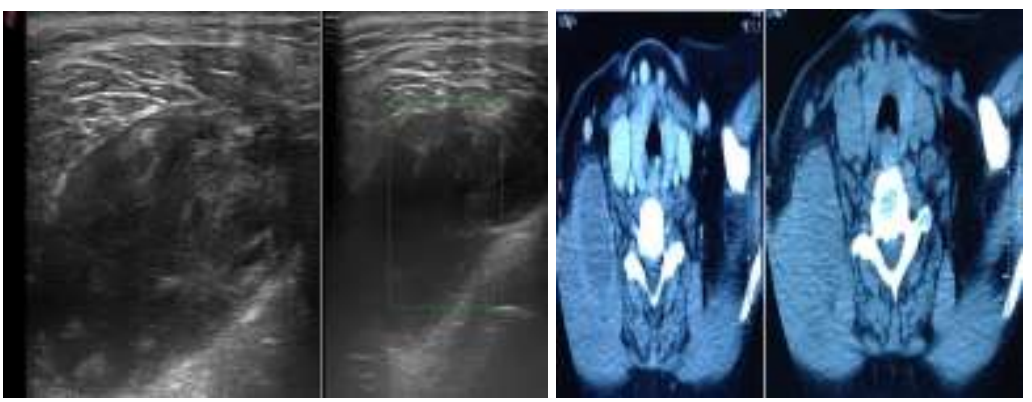

Fig 13: 65 years/F presenting a mass in right posterior neck proven to be hemangiopericytoma. USG (a) and CT Scan (b) reveals well circumscribed hypodense enhancing mass with cystic/necrotic component 


\section{Conclusions}

1. After nodal masses the thyroid masses, neurogenic tumours, paragangiomas, congenital/ developmental cysts and the salivary tumours are common occurrence presenting as neck mass.

2. Characteristic site and imaging features can clinch a diagnosis in almost all situations

3. Rare lesions like hemangiopericytoma should be kept in mind as differential diagnosis of neck masses.

\section{References}

[1]. Ezzat S, Sarti DA, Cain DR, Braunstein GD. Thyroid incidentalomas. Prevalence by palpation and ultrasonography. Arch Intern Med 154: 1994; 1838-40

[2]. Jindal U, Singh K, Baghla A, Kochaar A. Spectrum of head and neck swellings in rural a population based on Fine-needle aspiration findings. Int $\mathbf{J}$ of Head and Neck Surg 5(2); 2012

[3]. Reede DL, Whealan MA, Bergeron RT. Computed Tomography of the infrahyoid neck, Part II: pathology; Radiology 145: 1982; $397-402$

[4]. Lloyd RV, Buehler D, Khanafshar E. Papillary thyroid carcinoma variants. Head, Neck Pathol 5; 2011; 51-6

[5]. Kwak JY, Kim EK, Son EJ, Kim MJ, oh KK, Kim JY, Kim KI. Papillary thyroid carcinoma manifested solely as microcalcifications on sonography. Am J Roentgenol 189: 2007;227-31

[6]. Carlson GW. Surgical anatomy of the neck. Surgical Clinics North Am 73; 1993;837

[7]. Catalano P, Fang-Hui E, Som PM. Fluid-fluid levels in benign neurogenic tumours. Am J Neuroradiol 18; 1997; 385-7

[8]. Anil G, Tan T. CT and MRI evaluation of nerve sheath tumours of the cervical vagus nerve. Am J Roentgenol 197: 2011; 195-201

[9]. Win T, Lewin JS. Imaging chacteristics of carotid body tumours. Am J Otol 16; 1995; 325-8

[10]. Turkington JRA, Paterson A et al. neck masses in children. Br J Radiol 78;2005: 75-85

[11]. Mancuso AA, Hanafee WN. Nasopharynx and parapharyngeal space. Computed Tomography and Magnetic Resonance imaging of the Head and neck ( $2^{\text {nd }}$ ed). Williams and Wilkins, Baltimore 1985; 428-97

[12]. Mittal MK, Malik A, Surekha B, Thukral BB. Cystic masses of neck: A pictorial review. Indian J Radiol imaging 22; 2012; 334-43

[13]. Vallat- Decouvelaere AV Dry SM, Fletcher CD. Atypical and malignant solitary fibrous tumours in extra-thoracic locations: evidence of their comparability to intra-thoracic tumours. M J Surg Pathol 22; 1998; 1501-11 